with the criteria for suitability for shared care described in the joint working protocol for Hertfordshire (paid employment and accommodation). This is also supported original papers

by the finding that prescribing appointments and instalments for dispensing medication are in accordance to expectations. Shared care clients, by virtue of their stability are often seen fortnightly or monthly with pickup instalments at twice weekly, weekly or fortnightly intervals. The audit did not distinguish between types of accommodation (i.e. rented or owned property, living in a hostel or with friends), therefore results should be interpreted with caution. However, employment seems to be an important factor in differentiating the two groups of clients.

The audit reported here suggests that although the new General Medical Services contract has not increased treatment capacity within primary care, it has improved quality of treatment offered, and clients in shared care are more stable than clients in treatment with specialist services. Further work is required to develop ways of overcoming identified barriers preventing successful and effective implementation of the enhanced model of shared care services.

\section{Declaration of interest}

None.

\section{References}

COMMISSION FOR HEALTHCARE AUDIT AND INSPECTION (2006) Improving Services for Substance Misuse, a Joint Review. Commission for Healthcare Audit and Inspection.

DEPARTMENT OF HEALTH (1996) Reviewing Shared Care Arrangements for Drug Misusers. Department of Health Circular. EL (95) 114

Department of Health.

DEPARTMENT OF HEALTH (1998) The Task Force to Review Services for Drug Misusers. Report of an Independent Review of Drug Treatment Services in England. Department of Health.

DEPARTMENT OF HEALTH SCOTTISH OFFICE DEPARTMENT OF HEALTH, WELSH OFFICE DEPARTMENT OF HEALTH AND SOCIAL SERVICES, NORTHERN IRELAND (1999) Drug Misuse and Dependence: Guidelines on Clinical ManagementTSO (The Stationery Office).

NATIONAL TREATMENTAGENCY FOR SUBSTANCE MISUSE (2002) Models of Care forTreatment of Adult Drug Misusers. Part 2: Full Reference Report. National Treatment Agency for Substance Misuse.

Anna Marie Felice NorthWest Herts Community Drug and Alcohol Team, Hertfordshire Partnership Trust, Hemel Hempstead, ${ }^{*}$ Christos Kouimtsidis Section of Addictive Behaviour, Division of Mental Health, 6th floor, HunterWing, St. George's University of London, CrammerTerrace, London SW17 ORE, email:ckouimts@sgul.ac.uk

\title{
Primary consultation clinics in child psychiatry: an evaluation of referrers' views of the service
}

\author{
AIMS AND METHOD \\ To collate referrers' views on primary \\ consultations in child psychiatry, \\ feedback data were collected by \\ questionnaires over a 12-month \\ period.
}

\author{
RESULTS \\ Referrers found reports clearly \\ written, informative and helpful, but \\ wished for further, more direct \\ involvement, support and follow up, \\ and also for a clear plan of action for \\ the children referred.
}

\begin{abstract}
CLINICAL IMPLICATIONS
Primary consultation clinics should be further developed and audited in the future, in view of the recent changes in child and adolescent mental health services.
\end{abstract}

Consultation clinics in child and adolescent psychiatry are not uncommon. The consultation clinics in Derby were set up by the child and adolescent mental health service and serviced the area of central Derby, which has a population of 250000 . The service was provided by two psychiatrists and primary mental health workers.

The child and adolescent mental health services in Derbyshire are sectorised primarily into central Derby and surrounding rural area services. There are two bases in central Derby, with the Town House providing tier 3 services and the Mill providing tier 1 and 2 services and housing the mental health workers. At other bases, situated in the surrounding towns, the different tiers of service are mostly provided under one roof. Housing the primary mental health workers and therapists at two different sites created communication and logistical problems and stretched consultant psychiatric and managerial support. Central Derby has two full-time consultants, and the service receives over 800 referrals a year. The child psychological services are separately provided and based at the children's hospital site. There are currently no established learning disability services for children; this need is provided for by the generic child and adolescent mental health teams. Recruitment problems and the recent exodus of therapists and mental health workers due to governmental changes such as Agenda for Change (2004) and the extension of responsibility for child and adolescent mental health services to cover up to the age of 19 years, has placed further stress and strain on the generic teams. There is therefore now an urgent need for new ways of working for psychiatrists in child and adolescent mental health services teams, and consultation (rather than direct hands-on involvement 
with children and their families) seems contemporary and much needed.

\section{Method}

\section{The consultation clinics}

The consultation service was set up in 2004 and continued offering a service until 2006. The aim of the consultation clinics was to offer consultation to potential referrers and provide education and support for professionals already involved. We also hoped that the number of inappropriate referrals to the service could be reduced. Professionals were informed from the outset that they would be expected to continue to work with the families, and that the service offered was one of consultation. Only in special circumstances, after consultation, would a decision be made for the child and adolescent mental health service to take on the clinical responsibility of the case. Certain types of referrals to child psychiatry were selected as being particularly suitable for consultation rather than direct involvement. These were often referrals where a number of professionals from different agencies were already involved and where involvement of the child and adolescent mental health services could result in duplication of work and possible confusion of roles. In only a very small number of referrals (in two cases) was a child and adolescent mental health services worker already involved. Although the referrer was often seen to be seeking direct assumption of the case, consultation was thought to be the best line of approach by the intake team who managed the referrals. The referrer was informed about the decision to accept their referred child/family for consultation, an appointment letter sent to both referrers and patients and the referrer was asked to accompany the patient to the clinic. The referrer and patients were seen together initially and then separately. Use was often made of the two-way mirror (the referrer watching the parent/child and psychiatrist consultation, and often the parents observing their children talking to the professionals). We felt that this was a unique way of undertaking consultation, which is usually with the professionals and without the family. The clinics were held twice a week by the two psychiatrists, and primary mental health workers were encouraged to attend and take part. We are not aware of any similar model of consultation used in child and adolescent mental health services.

\section{The questionnaires}

Two types of questionnaires were sent; a general practitioner (GP) evaluation questionnaire and a referrer questionnaire to other professionals such as social workers, school nurses and community paediatricians. A total of 50 questionnaires were sent. The questionnaires asked seven questions (Box 1).

\section{Box 1. The questionnaire}

- Did the consultation provide the information that you were seeking?

(Referrers were asked to place a tick in four boxes marked 'Not at all,',Partly','Mostly' or 'Fully')

- Was the feedback clear? (Referrers were asked to tick a 'yes' or 'no' box)

- Was the feedback helpful? (Referrers were asked to tick a'yes' or 'no' box)

- Was the report clearly written? (Referrers were asked to tick a'yes or 'no' box)

- Was the report helpful? (Referrers were asked to tick a'yes' or 'no' box)

- What did you find most useful? (Referrers were asked to write down their comments on four blank lines)

- Do you have any suggestions for changing the consultation process?

(Referrers were asked to write down their comments on four blank lines)

\section{Results}

Of 50 questionnaires, 25 were received back; $96 \%$ (24 of 25 ) of the respondents thought the report that they had received was clearly written; $92 \%$ (24 of 25 ) thought it was helpful to them; $64 \%$ (16 of 25) thought it was helpful because of the information contained; $20 \%$ (5 of 25 ) thought it provided an assessment of their patient; and $16 \%$ (4 of 25 ) felt that the report was supportive. The referrers made some suggestions for change, such as wanting a 'clearly written plan for follow up and ongoing support'; 'a summary and actions rather than a report of who said what'; and 'a way to speed up the process of the waiting list'. Although they valued the information that they received from the consultation clinics, 64\% (16 of 25 ) were interested in more direct work and only $12 \%$ (3 of 25) were not.

\section{Discussion}

Black et al (1993) recognised that consultation offered by psychiatrists to other professions is an important and valuable use of their resources. Markantonakis \& Mathai (1990) showed that referring professionals are often poorly aware of the type of services offered by child psychiatric clinics. Consultation with other professions, such as nurses, social workers and health visitors, is therefore an excellent way to educate and empower them. Cheseldine et al (2005) showed that this can be valuable to nurses working with children and young people who have learning disabilities and/or autism. The skills of these professionals can be improved so that they can carry on trying to help their patients. Communication can be enhanced between primary care and specialist care providers. There is a recognised difference between consultation and supervision, but the two terms are often confused. Supervision is regularly provided by child psychiatrists, psychologists and other professionals to their colleagues, and is important in helping to maintain objectivity and safety in their clinical work. The supervisor is often professionally close to the worker involved. 
Consultation, however, is provided to the worker involved with the case in an indirect way. The person seeking consultation is seeking the consultants' views and

original papers comments and is 'picking their brains' about the case. The worker can then continue to work with the patient without handing the responsibility of the case to the clinic. Prior et al (2003) reported positive findings when consultation was used with health visitors. They reported that supervision also had a positive impact on the referral rates, increased health visitor competence and reduced feelings of isolation and vulnerability. Stallard (1991) highlighted the potential of consultation to sort appropriate from inappropriate referrals, thus helping to foster a more relevant referral pattern.

We suspect that many of the referrers may have seen the consultation clinics as a possible way of bypassing the waiting list for child and adolescent mental health services, which was substantial at the time of undertaking this survey. Despite this we did begin to see a slow change in referral patterns with some referrers starting to seek specifically a consultation rather than direct hands-on therapy for their patients. We found this hopeful; although most referrers still sought direct involvement from child and adolescent mental health services for their patients, $12 \%$ (3 of 25) did not. We hoped that this group of referrers felt empowered after the consultations and were able to continue to help their patients on their own. Perhaps some went on to seek help from a different, more appropriate agency. We also hoped that this meant that the service was spared a workload of $12 \%$ of the referrals, which would have gone to the tier 3 service. It is too early to predict the longterm effect on referrers in regard to change in their overall skills in helping such families and also the eventual change in referral patterns to child and adolescent mental health services.

We felt retrospectively that having two different questionnaires, for GPs and for other referrers, was a weakness in the study and that in future we would use a common questionnaire for all referrers. We sent feedback of the results of this study to referrers and to professionals working in child and adolescent mental health services. We hope to encourage more of the latter to continue to offer this service to future referrers, as we perceive potential benefits for referrers, for referred children and families, and for child and adolescent mental health services who are struggling to cope with the currently escalating number of complex and challenging referrals.

\section{Declaration of interest}

None.

\section{References}

BLACK, D., COTTRELL, D., KAPLAN,T., psychiatry Liaison child and adolescent (1991) An evaluation of general and Adolescent Psychiatry. Royal College of Psychiatrists.

CHESELDINE, S., MANDERS, S. McGOWAN, C. (2005) The role of consultation clinics in services for children and young people with learning disabilities and/or autism. Child and Adolescent Mental Health, 10, $140-142$.

DEPARTMENT OF HEALTH (2004) Agenda for Change: Policy and Guidance. Department of Health. (http://www.dh.gov.uk/en/ policyandguidance/ humanresourcesandtraining).

MARKANTONAKIS, A. \& MATHA
(1991) An evaluation of general practitioners' knowledge and satisfaction of a local child and adolescent psychiatric service. Psychiatric Bulletin, 14, 328-329.

PRIOR, H., STIRLING, H., SHEPHERD, K. et al (2003) Advantages of a staged consultation supervisory model for health visitors, from child clinical psychology. Clinical Psychology, 26, 32-35.

STALLARD, P. (1991) The development and evaluation of a health visitor consultation service. Clinical Psychology Forum, 44, 10-12.

Puru Pathy, Neelima Yanamani Senior House Officers in Child and Adolescent Psychiatry, Psychiatric Unit, City Hospital, Derby, *Aristos Markantonakis Consultant in Child and Adolescent Psychiatry, TheTown House, Green Lane, Derby DE1 1RZ, Paul Wilson Consultant Child and Adolescent Psychiatrist, Victoria, Australia, Russell Mason Clinical Governance Clinical Audit Coordinator, Kingsway Hospital, Derby

\section{MICHAEL BESSANT, ELIZABETH A. KING AND ROBERT PEVELER}

\section{Characteristics of suicides in recent contact with NHS Direct}

\section{AIMS AND METHOD}

NHS Direct is increasingly used as a first source of health advice and information, receiving an average of 600000 calls per month. We performed an audit of suicides in Hampshire and the Isle of Wight over a 2-year period to determine the characteristics of those who died by suicide and had been in recent contact with NHS Direct.
RESULTS

Of 278 suicides resident in Hampshire and the Isle of Wight, $30(10.8 \%)$ had contacted NHS Direct in the preceding year. Of the 30 callers within the preceding year, $12(40 \%)$ made multiple calls, $7(23 \%)$ called within 2 weeks of death, $9(30 \%)$ callers reported mental health problems, 17 (57\%) reported physical problems, and $4(13 \%)$ just requested information. Eighteen $(60 \%)$ calls resulted in urgent medical referral, 17 to a general practitioner and 1 to accident and emergency.

\section{CLINICAL IMPLICATIONS}

The high incidence of physical, often pain-related, problems merits further investigation. 